\title{
Making an urban university 'green': uniting administration and students towards synergy.
}

\author{
Aleksandr Fedorov, Evgeny Zakablukovskiy ${ }^{*}$ and Anna Galushkina
}

Minin Nizhny Novgorod State Pedagogical University, 1 Ulyanov St., 603950, Russia

\begin{abstract}
The authors study a case of increasing the environmental sustainability of Minin University. Specific obstacles found on the path of the 'green' development of urban universities is analyzed. Objective reasons for difficulties include the geographical position of the university, absence of traditional campus system, buildings' age and condition, limited availability of financial resources and legal grounds for restructuring of buildings; centralized sewerage, heating and water supply as well as waste disposal; plus, the relatively low level of environmental culture of the population. Even when an urban university 'inherits' these issues from the city itself, the authors see a real opportunity to improve the environmental sustainability of the university by implementing a system that includes environmental projects by the university administration blended with student initiatives. The university administration prepares the application for the 'green' rating, administers a contest of student projects and the allocation of resources for those, as well as the renovation and restructuring of university premises. Students are responsible for planning relevant student associations' agenda, generating ideas, participating in project workgroups, planning and driving environmental events. The authors conclude that it is possible to obtain a synergetic effect of the upstream development of the environmental sustainability of the university.
\end{abstract}

\section{Introduction}

One of the main obstacles crossing the path of the "green" development of urban universities in Russia is the geographic location of a university and, therefore, mainly severe temperature conditions, peculiarities of precipitation as well as insufficient sunlight amount for most of the year. All above does not allow using many resource-saving technologies. For example, there are only 25 sunny days per year on average in Nizhny Novgorod, while precipitation falls 253 days per year: that limits the possibility of using the sunlight as an alternative energy source, and at the average annual wind speed of $2.4 \mathrm{mps}$ it becomes economically costineffective to use industrial wind power plants [1]. In addition, Russian urban universities differ significantly in their format from traditional campuses located in Europe and in the US: there is no joint orderly infrastructure that would transform the university buildings into a single complex. Dormitories and educational buildings exist somehow 'separately' from each other, the utilities system forms part of the city network, and there is almost no green space. Thus, to a large extent, urban universities 'inherit' the problems of a settlement, and the situation is the same in many world countries [2]. The research performed under the auspices of the European Commission shows that in foreseeable future the population's desire to settle (and, accordingly, to receive higher education) within the urbanized territories will gradually increase: by 2020 , up to $80 \%$ of the European population will live in the urban environment [3], so the urban universities, as a phenomenon, is something we have to consider further for many decades or even centuries.

Minin University (Nizhny Novgorod, Russian Federation) is an urban institution with rich traditions, founded in 1911 in the historical part of the city. Most buildings of the university are part of the country cultural heritage, they are strongly protected by authorities and are not subject to radical restructuring: in accordance with the federal law requirements, the university may not carry out any works that would change the appearance of the buildings. This, in turn, entails the inability to bring buildings into full compliance with environment-friendly standards [4]. In particular, it is not possible to perform completely 'green construction' works which would ensure that the natural environment pollution is significantly reduced thanks to the renewable energy, water and other resources. The university founder is the Russian Ministry of Education and Science whose subsidies are primarily designed to pay for staff salaries, utilities and maintenance. Those funds are not enough to cover the cost of introducing expensive 'green' technologies. Centralized sewerage, heat and water supply does not allow the University to make full use of technologies designed for cleaning and reducing the use of water. Similarly, the situation with waste removal is mediocre: separate collection of garbage is fully driven only in the cities of s.c. federal significance (Moscow and St. Petersburg). There is a tendency to introduce the program in other regions, but there are no large-scale positive results at the moment. The sorted garbage, as a rule, eventually turns out to be stored at the citywide landfill and not processed 
separately. For the same reason, the ecological culture of the population is at a relatively low level: one-off events raise the 'recognition rate' of some environmental issues to some extent, but do not represent a serious environmental 'vaccination' of the population. The situation could possibly change with the opening of a unique (for this country) waste sorting plant in Nizhny Novgorod in June 2018. According to the authorities, the enterprise will allow to reduce the amount of waste sent to the dump site by $30 \%$. Initially, the sorting site will be working based on the Russian reality: individuals and legal entities lack systematic practice of separate garbage collection. In future, the system can be reconfigured, based on the changing market needs.

Despite the obstacles described, Minin University administration is making systematic attempts to improve the environmental sustainability of the school by building a system of interaction between the students and the management. In particular, we encourage implementing environmental projects suggested both by the university administration ('from above') as well as by the students ('from below'). It should be noted that the system works only when there are established internal communication channels and responsible supervision lines.

The university administration undertakes to develop and implement environmentally sound policies thought to minimize negative impact on the environment, including re-equipping premises, purchasing energysaving equipment, offering environmental education to its employees, launching new environmental courses and specialties, starting competitions on social and environmental projects for students, allocating resources for implementing winner-projects as well as administering the application process for UI GreenMetric rating.

The University administration also oversees its own Department of Environmental Education and Rational Nature Management. The Department is one of the oldest in Russia. Research activities run within the priority areas of scientific research at the University [5] as well as the areas preferred by the Russian Foundation for Basic Research which issues relevant grants. The work results are published in monographs, textbooks, teaching aids and scientific periodicals. Over the past three years, the Department has published more than 200 scientific articles, including those in journals that are indexed by the Web of Science and/or Scopus. The Department supervises the education of bachelors and masters in the following areas: 'Environmental Management and Audit', 'Environmental Design and Expertise', 'Theory and Methods of Teaching and Education (Ecology)'. There are also additional shortterm education programs such as 'Environmental Education for Sustainable Development', 'Ensuring Environmental Work Safety in the Field of Hazardous Waste Disposal'. The Department is responsible for carrying out specialized scientific events, e.g. an international scientific and practical conference 'Environmental Education for Sustainable Development: Theory and Pedagogical Reality', an interregional conference for undergraduate and graduate students
'Environmental problems and how to solve them: natural and socio-cultural aspects', regional student Ecology Olympics, city contests for school students on ecology. There is an association of educators teaching ecology in the Nizhny Novgorod region, an environmental analytical laboratory for monitoring and environmental protection and the 'Ecodesign of the urbanized megalopolis environment' research laboratory functioning on the basis of the Department. The laboratory is a technical complex consisting mainly of advanced physical and chemical devices used in modern environmental and analytical practice. The laboratory has implemented all stages of environmental objects analysis, from sampling and sample preparation to direct environmental analysis and data desk processing. The main environmental objects explored during the educational process and scientific work, are soils, plant biomass, water, food raw materials, waste and air masses. 'Ecodesign of the urbanized environment of the megalopolis' laboratory develops a strategy for designing and mastering the environment of a big city, providing a synthesis of cultural, ecological, humanitarian, artistic, scientific and technical directions of culture, in order to assist in harmonizing relations within the s.c. 'human-nature' system.

One of the significant achievements of the Department has been the active involvement of students who study ecology. As a result, two environmental student associations were created.

However, the key performance indicators of these student associations have been quite modest due to students having no or little experience in project activities. It was also difficult to obtain large volumes of input data for research from the economic services of the University, despite the existing initial experience of network cooperation and the usage of advanced ICT formats [6]. The University administration has decided to consolidate its efforts and the work of students, in particular for the implementation of the 'Positioning of Minin University in the UI GreenMetric Global Green Rating'. A steering committee consisting of the employees and the students of the University was created. The initial stage involved an in-house kick-off project session, where the project team distributed roles and responsibilities, drafted the project documents and discussed the global rating methodology. The R\&R distribution was organized as follows: students are responsible for the planned work of relevant student associations, for generating 'green' ideas, participating in working groups for the project implementation, organizing and driving student environmental activities, while the University administration takes care of collecting data and filling up the application for UI GreenMetric rating. At the second stage, an offline creative session was held to generate solutions: as a result, an initial pool of proposals was developed to improve the position of Minin University in UI GreenMetric rating. The third stage included conducting a full-time creativity and sorting session to discuss and sort out ideas. The events were driven in accordance with the s.c. design thinking methodology, adapted to the project situation by the students themselves [7] on the 
basis of the PMBOK. The solutions were discussed, clustered and carefully selected on the basis of the open in-class voting as a result of persistent three-hour long work. The fourth stage involves submitting projects to the intra-university student initiatives competition and receiving funds within the internal university grant system. The fifth stage consisted in organizing the interaction of the project team and relevant university administrative staff with the aim of collecting design data and developing preliminary feasibility study documents in order to implement selected solutions. At the end stage of the project, priority solutions will be presented to the senior management for approval. The presentation will include a feasibility study as well as calculation results for potential number of rating points, provided that the proposals are fully implemented. In addition, based on the interim report by the project managers, a number of decisions should be made regarding the appropriate adjustments needed for the University ecostrategy as a whole. Proceeding from the above written material, it is possible to draw a wellgrounded conclusion about the possibility of obtaining a synergy effect of bottom-up development in the direction of the environmental sustainability of an urban university by combining efforts and goodwill of all parties even in difficult objective conditions.

\section{References}

1. The climate in Nizhny Novgorod. Weather and climate monitoring in Russia, CIS and the world.
Available

online

at:

www.pogodaiklimat.ru/climate/27459.htm

(accessed on 19.02.2018).

2. D. J. Edelman, M. Schuster, J. Said, 2017. Urban Environmental Management in Latin America, 1970-2017. Current Urban Studies. 5, pp. 305-331.

3. Making our cities attractive and sustainable. How the EU contributes to improving the urban environment. Luxembourg: Publications Office of the European Union, $2010-36$ pp. doi: $10.2779 / 42720$

4. Federal Law No. 73-FL of June 25, 2002 'On the Objects of Cultural Heritage...'. Available online at: www.consultant.ru/document/cons_doc LAW_37318/(accessed on 19.02.2018).

5. The main directions of scientific activity at Minin University. Available online at: mininuniver.ru/scientific/scientific-activities/ schools (accessed on 19.02.2018).

6. E. Patarakin, S. Shustov, Digital Ecology: Social Networks and Informational Ecosystems. Vestnik Mininskogo universiteta. 3, pp. 13. (2013)

7. S. Goldman, Z. Kabayadondo, A. Royalty, M.P. Carroll, B. Roth. Student Teams in Search of Design Thinking. pp. 11-34// Design Thinking Research. Building Innovation Eco-Systems. Heidelberg: Springer, (2014). 